\title{
Discussing the Construction of Undergraduate Psychological Crisis Management System
}

\author{
Zhigang Gao \\ Hei Longjiang Engineering University \\ Harbin, China 150001 \\ Hei Longjiang University of Science and Technology \\ Harbin, China 150022
}

\author{
Yan Zhan \\ Hei Longjiang University of Science and Technology \\ Harbin, China 150022
}

\begin{abstract}
With the higher education of our country has turned into the development stage of popular, more and more young people can enter the universities for further study, the scale of internal student is expanding constantly, and at the same time, the undergraduates group of psychological problems and the psychological crisis is bigger and bigger, it brought certain pressure to the family, school and society. Therefore, it becomes an important content of the university management activities on how to carry through the crisis management in university and to minimize the loss caused by the crisis for students and school. This paper analyzed the connotation and manifestation of psychological crisis of the undergraduates, and also analyzed the specific problem of which existed in undergraduate psychological crisis management, a predictive method is applied to construct the undergraduate psychological crisis management system, and innovating the approach of how to construct undergraduate psychological crisis management system, the innovation point is integrating students, parents, teachers, school leaders into the undergraduates psychological crisis management system, and using modern science and technology, and broaden the channels of communication, uploading knowledge which is about mental health and psychological crisis management through the website of school, forum, QQ group, it enables the work of undergraduates psychological crisis management to focus on prevention, nip in the bud; Another innovation point is that another key point of construction of undergraduates psychological crisis management system is paying attention to the recovery phase after undergraduates psychological crisis, after the crisis need to follow and evaluate, and make students completely walk out of crisis shadow, and improve themselves.
\end{abstract}

Keywords-psychological crisis; management system; construction

\section{INTRODUCTION}

The research of campus crisis events originated the subjects- "Public Relations". The United States studied it at the earliest and had the most abundant research result. There are almost full-time institutions that study the campus crisis every state in the United States; it attaches importance to the management of the crisis from competent department to school. One of the most famous one is the Lerner "Combat Guide of Campus Crisis Response", it summarized the acute mental trauma for campus suicide, and campus drugs, accident harm, drug abuse, pregnancy trial marriage, sexual harassment etc. and carrying out the countermeasures study and training education. It has been known as a set of campus crisis comprehensive reaction plan.

Our country started to study the crisis later, the research of campus crisis management system was began at the end of 20th century. In 1994, Zhou Beilong proposed "the Crisis of China Education ", started the precedent of campus crisis research. Last ten years, some of the big cities appeared similar organizations such as psychological hotline, crisis intervention center, and suicide prevention center, but the importance of crisis management and crisis prevention has not been paid attention to, it made the research of crisis management and crisis prevention with the development of school and society out of step. According to the campus crisis, our country also made a series of laws and regulations, such as "the measure of student accident", "the temporary provisions of special major accident investigation procedure", "the rules of colleges and universities internal security work", "some opinions of ministry of education on further strengthening and universities students apartments management", "the investigation regulation of fire accident", "the provisional regulations of school accident of food poisoning administrative responsibility" and so on.

Throughout the domestic and overseas research status, the research of campus crisis management system was developed after great disaster and crisis accident, and most scholars focus on response and warning, after crisis the research of control processing and recover evaluation became very weak, the achievement was quite few. And every time after the crisis, it must bring trauma and destruction to the students and schools. Therefore, it is very important to maintain social stability and development for university crisis handling and recovery assessment work, and it will affect the confidence of people to the college administrators.

\section{THE CONNOTATION AND MANIFESTATION OF UNDERGRADUATES PSYCHOLOGICAL CRISIS}

\section{A. The Connotation of Undergraduates Psychological Crisis}

Undergraduates psychological crisis is refers to the undergraduates encountered events or situations beyond their 
resources and ability, individual cannot cope with and lead to a status of mental disintegration, it can bring about the individual behavior, emotion and cognition function disordering, the undergraduates which are in crisis status are easy to take place self-destruction and hurting others. Suicide and death are typical crisis events. Moreover such as violence invasion, losing relatives, sudden disaster, sexual assault also belong to the crisis events.

\section{B. The Manifestation of Undergraduates Psychological Crisis}

Undergraduates are in drastic changes of mind and body development, body and mind development has not been yet mature and lack of social experience, psychological endurance is worse, it is difficult to deal with various psychological conflicts in study and life. Especially when they face the special conditions from family, school, and themselves, and they cannot deal with the problems in previous ways, then it is easy to sink into panic, at this moment if there is not any help from the outside, some students will quickly slipped into crisis.

Undergraduates psychological crisis are mainly as follows:

First, psychological crisis caused by learning. University education is different from high school education, living through the nervous university entrance exam, after entering university, every course has faster schedule and more difficult than high school, and it's hard to adapt to this for freshman right now, even if they adapted but also face whether major matches own interests, in addition the independent learning ability is insufficient, the pressure of competition is increasing, the role position changed, part of the undergraduates appear anxiety, lack of attention, forgetfulness and examination anxiety and other problems, some even appear disgusted phenomenon of skipping classes and surfing the internet.

Second, the psychological crisis caused by family economic. With the rapid development of market economy, the university logistic eatery becomes socialization and rising prices cause that undergraduates from poor areas is difficult to maintain normal study life, part of students in order to maintain basic study life, they have to use extracurricular time to take a part job, comparing with the students with good condition will have a potential inferiority complex.

Third, the psychological crisis caused by interpersonal communication. Because contemporary undergraduates most are the only child, coddling since childhood, relatively speaking, they all have dependent psychology and selfish tendency, when they are in one room, the conflict arises spontaneously.

Fourth, the psychological crisis caused by emotional issue. Love phenomenon has become a commonplace sight in campus. There is love, there is also heartbreaking, when facing the emotion problems, undergraduates lack more rationality, as time passes, after the setback of personal emotion it will appear unusual psychology or behavior, caused a series of emotional crisis.

Fifth, unpredictable crisis, such as the collective food poisoning, the group traffic accident, the infectious diseases spreading, fire earthquake and natural disasters, casualties, these crises have groupmate and unpredictability.

\section{THE CONNOTATION AND SitUATION OF UndERGRADUATES PSYCHOLOGICAL CRISIS MANAGEMENT}

\section{A. The Connotation of Undergraduates Psychological Crisis Management}

Undergraduates psychological crisis management is point to deal with relevant mechanism of undergraduates psychological crisis, universities in order to avoid or reduce the grievous injury and threats produced by undergraduates psychological crisis, formulating and implementing organized and planned a series of management measures and corresponding strategies, including the evasion of psychological crisis, the control of psychological crisis, the solution of psychological crisis and the revival of psychological crisis.

\section{B. The Status of Undergraduates Psychological Crisis Management}

Undergraduates psychological crisis events will not only threaten normal teaching and life order, but also damage the image and reputation of university, the stability and the development of university will be influenced..

The main problems of undergraduates' psychological crisis management are:

1) First, the psychological crisis management system is not well organized: In the colleges and universities of psychological crisis management system is not perfect, lacking of policies and regulations of crisis management, many crisis events still stay on the experience groping stage; There is no specific plan of psychological crisis management, it doesn't form working system and working mechanism including the crisis warning, crisis recognition, crisis intervention, crisis management, crisis after treatment; There is no standard procedures for crisis management and crisis processing, in order to guide related students, teachers and parents to cope with crisis events; It doesn't bring related personnel into school psychological crisis management system, forming comprehensive crisis response networks.

2) Second, the crisis management consciousness of university leaders and teachers and students is weak: Some university leaders and teachers pay insufficient attention to crisis management problems, they considered that the primary responsibility of universities is doing well on teaching activities, for the students' psychological crisis are in normal range, even if it is according to the proportion that also has the possibility. At the same time, all levels personnel of university lack of education and training of 
crisis management, some leaders and teachers thought that the crisis management was how to dispose after crisis event. Students compared with teachers, they lack of more crisis management knowledge and awareness.

3) Third, shortage of psychological crisis management of relevant personnel: The school leader, department leader, instructors, teachers, students' parents, student cadres, dormitory classmates, dormitory manager are important members in each section of school psychological crisis management. Anyone of them has the chance to find crisis, but because of the above personnel didn't get special training, lacking of the knowledge of crisis intervention, even if they met the psychological crisis phenomenon that also couldn't report to the relevant personnel in time, the crisis events can't get promptly decisive processing, thus turning into tragedy.

4) Fourth, after the crisis it is short of the corresponding tracking and evaluation: At present universities have solved the students crisis events successfully, usually make little the tracking retention and summary evaluation. They thought that as long as the student got out of the crisis events everything will be all right, after students went through the crisis, there is still a shadow in psychology, it need teachers to communicate frequently, so as to consolidate efficacy and complete personality.

\section{AN EFFECTIVE WAY TO BUILD UNDERGRADUATES PSYCHOLOGICAL CRISIS MANAGEMENT SYSTEM}

\section{A. Improve the Understanding, to Complete Undergraduates Psychological Crisis Management System}

If undergraduates psychological crisis events would not be resolved successfully, it could lead to students suicide or hurt others, not only cause irreparable loss to undergraduates, but also hurt students' family, school and society, therefore, university departments should put a new premium on management problems of undergraduates psychological crisis, standing on the height of stability of school and social to recognize undergraduates psychological crisis. Meanwhile, colleges and universities should plan undergraduates psychological crisis management work, forming the undergraduates psychological crisis management system which included the crisis warning, crisis recognition, crisis intervention, crisis management, crisis assessment summary, working out the normative crisis management and crisis processing procedures, it can provide reference and basis for related students, teachers and parents.

\section{B. Carrying out the Theory Training and Research of Undergraduates Psychological Health and Psychological Crisis Management}

It is an important task to strengthen relevant personnel training of crisis management knowledge. Every university need carry out education activities on mental health and mental crisis management, it can invite experts to make theory training, and it can also choose relevant personnel such as instructors, teachers, psychological committee member, psychological counselor to discussing around a topic, so it can achieve the function of prevention, and it can also make mental health problems of students to be solved, it would positively impact the healthy growth of undergraduates.

\section{Innovating the Carrier of Theory Study, and Broadening the Channels of Undergraduates Psychological Crisis Management System}

Each university can hold various psychological lectures, mental health knowledge exhibition, but also can establish psychological website by using the school forum and QQ group to upload mental health and psychological crisis management knowledge, at the same time, by building the students' psychological community, and developing various psychological salon, counseling and group mental training activities, propagandizing mental health and psychological crisis management knowledge widely, in order to improve the quality of psychological health and psychological crisis management.

\section{Paying Attention to the Psychological Crisis Warning, Developing Enthusiasm of Involvement of People}

Paying attention to the psychological crisis warning ability and helping the students of psychological problems to pull through, controlling the further development of psychological crisis events, the key is to establish a higher quality of psychological crisis management team. Therefore, by strengthening the training of instructors, teachers, class psychological members, the dormitory psychological liaisonman, students mainstay, dormitory management personnel to improve the ability that they find and distinguish crisis, identify the ability of crisis; At the same time, strengthening the communication between parents and students, setting up network platform with the parents of students so as to interflow psychological trends of students, it can make the parents of the students to focus on children study and mental health, enhancing education and guidance of psychological intervention consciousness and intervention skills, in order to form support system that consists of instructors, teachers, students mainstay, class psychological members, dormitory psychological liaisonman, dormitory management personnel and students' parents threedimensional network, so we can achieve to find early, interments early, change early and treat early.

\section{E. After Crisis Disposing to Conduct Tracking and} Returning Visit, Summarize the Evaluation Timely

The crisis party will relieve a little bit after crisis happened, but psychological shadow caused by the crisis existed objectively, it will appear again and again in the party's later life, once the new stimulus or events take place, it will bring the people back to the feeling of crisis, so it need follow up and return visit who in the crisis, and knowing its psychological trend timely, to help undergraduates to walkout of the shadows and improve themselves. In addition to it should summarize and evaluate promptly for proposed 
crisis events, so as to provide reference and basis for relevant crisis events.

\section{CONCLUSION}

Undergraduates psychological crisis management is a systematic and complicated job, this system has important function for protecting undergratuates in psychological crisis and protecting the stability of university and society, it should cause social attention, and researching and exploring actively, finally, making out of a feasible management system and working mechanism of unergraduates psychological crisis, so as to guide specific crisis events of universities.

\section{REFERENCES}

[1] Zhang Chengbin. "The Enlightenment of Hayne Law on Psychological Crisis Administration Concerning College Students", Chinese Medical Ethics, 2011,8,vol. 24 (In Chinese)

[2] Lin Ke. "Thinking and Countermeasures of Undergraduates Psychological Crisis Management" Journal of Hunan Junior College, 2010.(2): pp 150 - 152. (In Chinese)

[3] Xie Gonglin, Effective Approach of Undergraduates Psychological Crisis Management , "Educational World", 2010 (4) (In Chinese)

[4] Li Jian, Construction of Prevention and Early Warning System Colleges and Universities, Heilongjiang Researches on Higher Education, 2010 (3) (In Chinese) 